\title{
NITROGEN WORKSHOP SPECIAL ISSUE PAPER Concluding Editorial: Conclusions of the 17th International Nitrogen Workshop
}

The workshop addressed the increasingly important issue of global food security and the role that nitrogen (N) has to play in ensuring that sufficient food is produced to meet the demands of an increasing global population. The past 50 years have seen dramatic changes in food production. In the coming 50 years it is likely that global populations will plateau at around 9-10 billion people, with food demand outstripping this growth. At the same time there is increasing demand to improve the sustainability of agricultural production through the reduction of reactive $\mathrm{N}$ losses to the environment. Research on improving $\mathrm{N}$ utilization and reducing losses to the environment has been on-going since the early 1980s, when the first Nitrogen Workshop was convened. However, there still appears to be a gap between current scientific knowledge and best farming practice, indicating a deficit in terms of communication and knowledge transfer.

The 17th Nitrogen Workshop aimed to address issues pertaining to food security and reducing reactive $\mathrm{N}$ losses to the environment. The 265 delegates were mainly from Europe, the Americas, Oceania and Asia, and came from a range of backgrounds including researchers, farmers/farm advisors, policy makers and industry. This wide range in both professional backgrounds and geographic spread represented a unique opportunity to gauge expert opinion through a quantitative survey that was carried out during the main auditorium and workshop sessions, covering four thematic areas. The survey produced a unique insight into the expert opinions of researchers and non-researchers across the world. Some specifics can be found at the end of these concluding remarks, and the full results of auditorium and workshop questions are available in online Supplementary materials 1 and 2, respectively (available at: http://journals. cambridge.org/AGS).

Nitrogen cycling in agricultural systems has been the subject of extensive research over the past 40 years: the driver for this research has changed from agronomic to environmental issues and more recently to sustainable food security. The low $\mathrm{N}$ use efficiency within livestock systems was highlighted by delegates but they were pessimistic about how far $\mathrm{N}$ use efficiency could be improved, based on scientific limitations. Mitigation of $\mathrm{N}$ losses to the environment was possible using the measures currently known and applied globally, but often at a cost to the producer.

Where there is a demand for a product, the market forces will adjust accordingly. Overwhelmingly delegates identified that demand-side measures, such as changing human protein consumption patterns, were the key to reducing demand for low-efficiency protein products but they felt that was unlikely to occur in a scenario where global population growth is linked to increased affluence in developing countries. Delegates agreed that education was one of the key methods for changing protein consumption patterns and that policies should be implemented to reduce demand for $\mathrm{N}$-intensive food products. Linking food choice and $\mathrm{N}$ footprint to the impact of protein consumption choice on human health is likely to be an effective approach to modifying consumption patterns.

There is a substantial body of knowledge in relation to $\mathrm{N}$ cycling in agricultural systems. Often there is a barrier between knowledge and the impact that knowledge has on the end user or the stakeholder. Delegates identified that trust between the stakeholders and the researchers was the most important factor for effective knowledge transfer and implementation of change. The pressure on researchers to publish scientific papers came through as a key driver and a potential barrier for implementing change at farmer level. The majority of researchers felt that more focussed research was required, whereas the majority of non-researchers indicated the opposite. This clearly highlighted the difference in drivers between the two groups.

The challenge for agriculture to continue to meet the increasing demand for sustainably produced food to meet the growing demands for animalprotein-based foodstuffs affects both agricultural, environmental and social scientists. Agricultural 
systems can be further optimized to increase efficiencies and reduce damaging losses of $\mathrm{N}$ to the environment, but there is a limit to how much further this can be achieved due to the large increase in production costs. Tempering the demand for food products with higher environmental footprints is key to reducing losses to the environment and underpinning a viable agricultural industry. Research should focus on the impact of knowledge generation on practice adoption while producing new science for publication.

\section{THEME I - ADVANCES IN UNDERSTANDING N-FLOWS AND TRANSFORMATIONS}

Research studies cannot account for all of the terrestrial $\mathrm{N}$ balance: most delegates thought that the gap was due to a poorly quantified component and/or measurement uncertainty. However, those with an arable/cropping background thought that much more $\mathrm{N}$ could be accounted for than those from a livestock or policy background. Most delegates ranked crop uptake as the largest $\mathrm{N}$ pathway, followed by loss to water and denitrification. The reactive $\mathrm{N}$ loss with the greatest policy relevance was thought to be loss to water, followed by ammonia $\left(\mathrm{NH}_{3}\right)$ and nitrous oxide $\left(\mathrm{N}_{2} \mathrm{O}\right)$ emissions. Delegates indicated that episodes of $\mathrm{N}$ loss could be better predicted and most indicated that a better understanding of microbial mediators could improve this prediction. The majority of delegates indicated that denitrification $\left(\mathrm{N}_{2} \mathrm{O}\right.$ and $\left.\mathrm{N}_{2}\right)$ had the largest uncertainty and that further research should focus on this topic. The greatest contributor to this uncertainty was thought to be spatial variability in soil and measurement methodology.

\section{THEME II - AHOLISTIC APPROACH TO UNDERSTANDING IMPACTS OF N ON THE ENVIRONMENT}

Nitrogen is not utilized as efficiently in animal systems as within cropping systems due to inefficiencies within the animal, which excretes non-utilized N. The majority of delegates agreed that changing human protein consumption patterns is the key to reducing total reactive $\mathrm{N}$ losses to the environment, but did not think that it would actually be possible to achieve. Delegates felt that the best policy measure to encourage this change would be via increased public awareness and education, followed by restrictions on animal numbers and the use of $\mathrm{N}$ foot- printing. It was generally felt that current $\mathrm{N}$ mitigation options would be able to reduce reactive $\mathrm{N}$ losses to acceptable levels, although a significant minority strongly disagreed. The main barriers preventing mitigation of reactive $\mathrm{N}$ loss to the environment were considered to be financial, knowledge transfer barriers and farmer acceptance. Most delegates felt that integration of $\mathrm{N}$ policies was the best way to increase the uptake of synergistic measures to reduce $\mathrm{N}$ losses, followed by food pricing and $\mathrm{N}$ foot-printing.

\section{THEME III - GLOBAL PERSPECTIVES ON N AND FOOD SECURITY}

Most delegates agreed that society can contribute to meeting global food demands, while protecting environmental quality. There were significant regional differences: researchers from Northern and Mediterranean regions of Europe were more optimistic than participants from UK/Ireland, and Western, Central/Eastern Europe, possibly due to the dominance of dry-land agriculture in the Mediterranean and the high level of regulation in northern Europe. Delegates were less certain as to whether sustainable intensification could be achieved within agricultural systems. In a post peak oil era, delegates felt that increasing the purchase price of fertilizer would not threaten food security, but any coupling of fertilizer price with environmental and health costs would.

\section{THEME IV - KNOWLEDGE TRANSFER}

There is a perception that many of the solutions to improve $\mathrm{N}$ use efficiency and reduce reactive $\mathrm{N}$ losses to the environment are known but that a communication barrier may prevent adoption at farm level. Many delegates indicated a need for more detailed, focused research but there was a significant difference in opinion based on delegate's background: around half of the researchers agreed while the majority of non-researchers disagreed. Trust between researchers and stakeholders was identified by many delegates as the most important factor for effective knowledge transfer and widespread implementation of change at farm level, but researchers appear to have significantly less contact with stakeholders than non-researchers. Most delegates agreed that there was a conflict between different drivers of research to meet the requirements of agricultural stakeholders, 
and most delegates felt that researchers should limit the number of their publications to $\leqslant 2$ papers per year.

\section{SUPPLEMENTARY MATERIAL}

The supplementary material for this paper can be found at http://journals.cambridge.org/AGS
With many thanks to the remaining members of the Scientific Committee - David Wall, Stanley Lalor, James Humphreys, Rogier Schulte and John Bailey.

K. G. RICHARDS, C. J. WATSON, R. J. LAUGHLIN, C. BUCKLEY, G. J. LANIGAN AND O. FENTON 